\title{
Mechanisms of Particle Coarsening and Phase Transformation in Oxide Dispersion Strengthened Steels During Friction Stir Welding
}

\author{
Keith E. Knipling ${ }^{1}$, Bradford W. Baker ${ }^{2}$, Daniel K. Schreiber ${ }^{3}$
}

1. U. S. Naval Research Laboratory, Multifunctional Materials Branch, Washington, DC 20375

2. U. S. Naval Academy, Mechanical Engineering Department, Annapolis, MD 21402

3. Pacific Northwest National Laboratory, Energy and Environment Directorate, Richland, WA 99352

Oxide dispersion-strengthened (ODS) steels are attractive materials for use in a wide variety of hightemperature power production applications including fusion and fission reactors, space energy applications, and conventional power plant components. Their high-temperature strength and radiation damage resistance is a result of nanoscale dispersed oxides, which pin grain boundaries and dislocations while also providing sinks for hydrogen and helium atoms, mitigating radiation-induced swelling. Traditional fusion joining processes are unsuitable for these alloys, because the oxide particles agglomerate during melting. Friction stir welding (FSW) is a solid-state joining process thought to prevent these deleterious effects, but we present experimental evidence of yttrium oxide particle agglomeration, coarsening, and transformation after FSW of a MA956 ODS steel. This yttrium oxide particle evolution is particularly interesting in aluminum-containing ODS steels, like MA956, because the original $\mathrm{Y}_{2} \mathrm{O}_{3}$ dispersoids react with oxidized aluminum in the metal matrix, producing various $\mathrm{Y}$ Al-O particles. These include yttrium aluminum monoclinic (YAM, $\mathrm{Y}_{4} \mathrm{Al}_{2} \mathrm{O}_{9}$ ), yttrium aluminum perovskite ( $\mathrm{YAP}, \mathrm{YAlO}_{3}$ ), and yttrium aluminum garnet ( $\mathrm{YAG}, \mathrm{Y}_{3} \mathrm{Al}_{5} \mathrm{O}_{12}$ ), which form at progressively higher temperatures [1,2]. Using scanning electron microscopy (SEM), energy dispersive spectroscopy (EDS), small angle x-ray scattering (SAXS), and atom-probe tomography (APT), we study the significant oxide particle coarsening that occurs during FSW of Al-containing ODS steels, which is a result of Ostwald ripening and continued phase transformation within the $\mathrm{Al}_{2} \mathrm{O}_{3}-\mathrm{Y}_{2} \mathrm{O}_{3}$ system.

APT reconstructions of the base metal and weld nugget microstructures are displayed in Figure 1. The base metal, Figure 1(a), consists of small Y-Al-O particles with an average diameter of $7.2 \mathrm{~nm}$. This agrees well with particle sizes measured by SEM and SAXS. Based on their composition, these are believed to be $\mathrm{YAlO}_{3}$ (YAP). There is also a larger elongated Y-Al-O particle that is identified as $\mathrm{Y}_{4} \mathrm{Al}_{2} \mathrm{O}_{9}$ (YAM). After welding, these particles agglomerate and coarsen into $~ 350-400 \mathrm{~nm}$ diameter particles, as measured by SEM. One such agglomerated Y-Al-O particle is displayed in the reconstruction in Figure 1(b). The interior of this particle contains four $\sim 40 \mathrm{~nm}$ diameter regions that are believed to be $\mathrm{Y}_{4} \mathrm{Al}_{2} \mathrm{O}_{9}$ (YAM), based on their low $\mathrm{Al}$ concentration. We hypothesize that these were discreet oxides in the original base metal that agglomerated and coarsened during FSW. Surrounding these "inner oxides" is an Al-rich oxide that is likely $\mathrm{YAlO}_{3}$ (YAP) or $\mathrm{Y}_{3} \mathrm{Al}_{5} \mathrm{O}_{12}$ (YAG), which are the Y-Al-O oxides that form at higher temperatures.

Diffusion of Al from the matrix to the particles is believed to be a critical mechanism in the Y-Al-O particle transformation and growth, and this is borne out by the slightly depleted Al concentration in the weld nugget matrix (8.956(3) at.\% Al) compared to that of the base plate $(8.968(5)$ at.\% Al). The significant amount of S observed throughout the agglomerated oxide may be an intrinsic impurity in the steel, or perhaps was introduced during welding. 


\section{References:}

[1] BW Baker and LN Brewer, JOM 66 (2014), p. 2442.

[2] BW Baker et al, Metallurgical and Materials Transactions E, 1 (2014), p. 318.

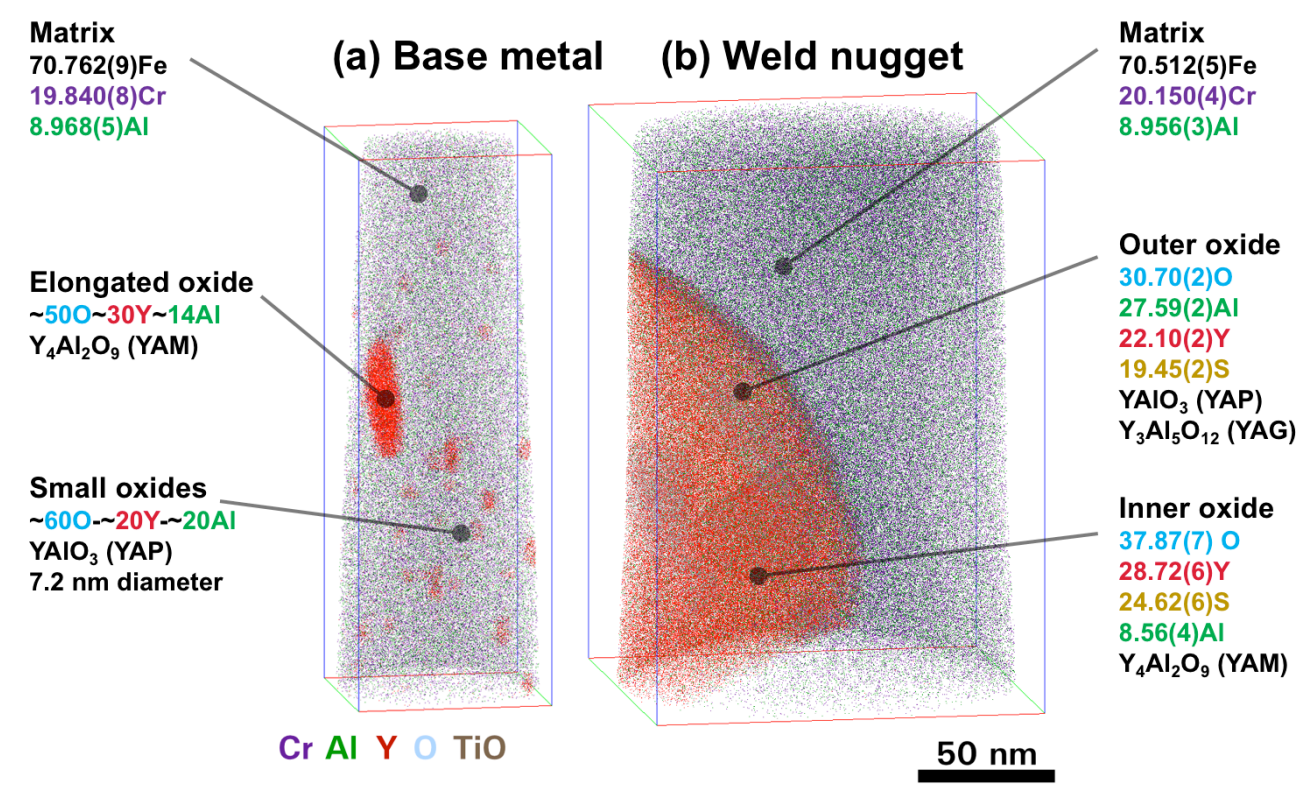

Figure 1. APT reconstructions of the MA956 ODS steel before and after friction stir welding. The individual phases are labeled, and their compositions (in at.\%) are indicated. 